\title{
RELATIONSHIP BETWEEN SOCIO-DEMOGRAPHIC VARIABLES AND RISKY SEXUAL BEHAVIOUR AMONG UNDERGRADUATES IN TERTIARY INSTITUTIONS IN RIVERS STATE, NIGERIA: A CROSS-SECTIONAL SURVEY
}

\author{
Eunice Ogonna Osuala ${ }^{1}$, Oluebubechukwu Amarachukwu Udi ${ }^{*}$, Idang Neji Ojong² \\ and Elizabeth Nnenda Oduali ${ }^{3}$ \\ ${ }^{1}$ Department of Nursing Science, Faculty of Allied Health Sciences, PAMO University of \\ Medical Sciences, Port Harcourt, Rivers State, Nigeria. \\ ${ }^{2}$ Department of Nursing Science, Faculty of Allied Medical Sciences, University of Calabar, \\ Calabar, Cross River State, Nigeria. \\ ${ }^{3}$ Department of Nursing Science, Faculty of Clinical Sciences, University of Port Harcourt, \\ Port Harcourt, Rivers State, Nigeria. \\ *Corresponding Email: oudi@pums.edu.ng; Tel: 08064328040.
}

Cite this article:

Eunice O.O.,

Oluebubechukwu A.U., Idang N.O., Elizabeth N.O. (2021), Relationship Between SocioDemographic Variables and Risky Sexual Behaviour among Undergraduates in Tertiary Institutions in Rivers State, Nigeria: A CrossSectional Survey. African Journal of Health, Nursing and Midwifery 4(5), 102-111. DOI: $10.52589 / A J H N M-$ SHTRPJPG.

\footnotetext{
Manuscript History

Received: 20 Aug 2021

Accepted: 8 Sept 2021

Published: 16 Sept 2021

Copyright $(92020$ The Author(s). This is an Open Access article distributed under the terms of Creative Commons AttributionNonCommercial-NoDerivatives 4.0 International (CC BY-NC-ND 4.0), which permits anyone to share, use, reproduce and redistribute in any medium, provided the original author and source are credited.
}

ABSTRACT: Background: Significant empirical surveys have been made to investigate sociodemographic factors contributing to Risky Sexual Behaviours among young people. However, there are concerns regarding what influences Risky Sexual Behaviours. The purpose of the study is to examine the relationship between the sociodemographic variables and Risky Sexual Behaviours among undergraduate students in tertiary institutions. Methods: A cross-sectional study was conducted among undergraduate students at two tertiary institutions in Rivers State, Nigeria to investigate the relationship between sociodemographic variables and Risky Sexual Behaviours. Undergraduate students in years one and two from departments of Nursing Science and Medicine and Surgery in PAMO University of Medical Sciences and University of Port Harcourt, College of Medicine were recruited for the study. Two hundred and eighty (280) undergraduate students were randomly selected from a total of 491 as participants in the study. Descriptive and inferential analysis of data using SPSS version 20 was done. Results: Data showed that $60 \%$ of the respondents were from the University of Port Harcourt, while $40 \%$ were from PAMO University of Medical Sciences. The majority of the students (78.9\%) were between 16 -20years, while only $0.7 \%$ of the students were $\geq 31$ years. Findings revealed that there is no significant relationship between respondents' sociodemographic variables and awareness of, attitude to risky sexual behaviour. It was found that only gender and age significantly influence practices with an R2 of 0.22. Conclusion: Risky sexual behaviour among young people is significantly associated with age and gender.

KEYWORDS: Risky Sexual Behaviour, Undergraduate Students, Socio-Demographic Variables, Tertiary Institutions. 


\section{INTRODUCTION}

\section{Background}

The foundation of any society is the youth. Students of tertiary institutions form part of this group and have the human right to exercise their sexuality. A study conducted in 2016 [1] affirmed that high social and economic crises become manifest when the sexual and reproductive health of youths are ignored. There is great concern regarding the prevalence and global trend of risky sexual behaviours which has become the focus of discussion including its attendant health implications. The social engagements of teens and young adults apparently predispose them to risky sexual behaviour than adults because of pressure/influence from their peers. A good understanding of factors contributing to risky sexual behaviour among undergraduate students may rebirth the development of intervention strategies and policies focused on improving their sexual behaviour.

With the expansion of higher education in developing countries, it [2] was recorded that it is important to understand the force that influences youth education and how these forces interlink to the universities. Global view of people within the age group of 15-24 years reveals that sexuality and sexual behaviour are of great concern.[3]

Sexual behaviour is any activity that may be solitary or involve more persons but generates sexual arousal.[4] The sexuality of people may be conveniently categorized according to the number and gender of the participants. Solitary sexual behaviour involves only one individual while sociosexual behaviour involves more than one person.[4]

There are a number of ways to define the risky sexual behaviour of youths. Glen-Spyron [5] recorded the most widely used definition for risky sexual behaviour as "unprotected vaginal, oral, or anal intercourse" while Center for Disease Control [6] and prevention in 2016 also defined risky sexual behaviour as "a behaviour that increases one's risk of contracting Sexually Transmitted Infections (STIs) and experiencing unintended pregnancy". A common definition of Risky sexual behaviour is a behaviour that increases the susceptibility of an individual to problems related to sexuality and reproductive health.[7] They include having sexual intercourse at an early age, having multiple sexual partners, having sex while under the influence of alcohol or drugs and unprotected sexual behaviours. They are the most common problems in adolescents and young adults which may expose individuals to permanent social, economic, psychological and physical problems.[7]

It is believed that university students are assets of a nation and potential agents to address the gap in the past and on whom the future national development and the entire generation is based. This fraction of the society is on the way to transforming to adulthood with great ambition. Unless appropriate age and institution targeted interventions exist, certain behaviours and acts of the students can place them at greater risk of STI including HIV and unwanted pregnancy.[5, 6]

A study [8] was carried out on "understanding risky sexual behaviour among Nigerian female university students". It used descriptive and inferential statistics to analyze the quantitative data. A high prevalence of unprotected sexual intercourse was reported and was not associated with age, year of study, place of residence and religion. A study by Odimegwu and Dolapo [9] was carried out to determine the ethnicity, gender and risky sexual behaviour among Nigerian youths. The study examined the relationship between ethnicity and youth sexual reproductive 
health, proxied by age at sexual debut, multiple sexual partners (MSP) and condom use at last sexual activity, among the 6304 females and 1549 males who reported being sexually active in the four weeks preceding the survey. The results showed that the median age at first sexual activity was 16 for females and 17 for males, $43 \%$ of male youths used condoms in their last sexual activity, compared to only $16 \%$ among females and a higher number of males $(81 \%)$ had multiple sexual partners compared to females (35\%). For females, elevated risks of first sex were higher among Hausa/Fulanis aged 15-19 and elevated risk of first sex was higher among Yoruba males. Hence, the need to put in place social, cultural and gender-specific tactics in order to promote protective sexual behaviours and prevention of sexually transmitted infections among youths in Nigeria.[9]

A study [10] conducted among 200 undergraduate students of Niger Delta University recorded that risky sexual behaviour were associated with age $(\mathrm{OR}=83.962, \mathrm{p}<0.01)$, ethnic group $(\mathrm{OR}=130.612, \mathrm{p}<0.05)$ and monthly allowances $(\mathrm{OR}=83.962, \mathrm{p}<0.05)$. In addition, the study findings particularly on sociodemographic characteristics of the respondents revealed that age had the most statistically significant association with risky sexual behaviour. Specifically, those in the age range of 18-22 years old are 84 times more likely to engage in risky sexual behaviour compared to those who are below 18 years old. Among the ethnic groups, respondents from Urhobo ethnic group were 130.6 times more likely to engage in risky sexual behaviour than those from Yoruba.

In a study [11] titled Socio-Demographic, Economic and Psychological Correlates of Risky Sexual Behaviour among Sexually Active Young People in Nigeria, data opined that $66 \%$ of the youths have had sex before reaching 18 years, $77 \%$ had unprotected sex, and $32 \%$ have had more than one lifetime sexual partner. It recorded that the significance of the association between socio-demographic (age, sex, marital status, ever fathered/mothered, awareness of AIDS, ethnicity, residence, and region), economic factors (employment status and wealth index), and risky sexual behaviour differ by the category of risky sexual behaviour. In all, psychological factor (satisfaction with life) was a significant correlate of the lifetime number of sexual partners. Their study concludes that socio-demographic, economic, and psychological factors were predictive of risky sexual behaviour among young people in Nigeria. However, the significance of these predictors differs by type of risky sexual behaviour.

The association of specific sociodemographic factors to risky sexual behaviours is not quite established in developing countries including Nigeria. Hence, the findings of this study may reflect the realities of sociodemographic factors contributing to risky sexual behaviours among students in tertiary institutions. Furthermore, this may prompt the need to establish and scale up sexual and reproductive health $(\mathrm{SRH})$ programmes in tertiary institutions of Nigeria based on the established relationships.

\section{Methods}

Study design: A cross-sectional study using a quantitative-descriptive design was used.

Study setting: PAMO University of Medical Sciences and the University of Port Harcourt both in Port Harcourt, Rivers State.

Study population: Year one and two medical and nursing students of both institutions. A total of 280 students were selected from 491 using the Yaro Yamanes sample size formula. 
Sampling technique: Proportionate sampling technique was used followed by simple random sampling using balloting to select 189 medical students and 91 nursing students from the two institutions.

Instrument for data collection: Data was obtained using a validated questionnaire adapted from the World Health Organisation survey instrument which was pooled to examine the relationship between respondents' sociodemographic characteristics and Risky Sexual Behaviors.

Reliability: Test re-test reliability of the instrument was conducted and the two scores were correlated using Pearson product-moment correlation and a value of 0.8 was obtained.

Ethical consideration: The Ethical Review Committee of the University of Port Harcourt, Rivers State Nigeria (UPH/CEREMAD/REC/MM61/025) gave approval for the survey. Participants were informed about the study objective. They were assured of confidentiality and their right to opt-out of the study at any point during the survey.

Data analysis: The research questions were analyzed with descriptive statistics while results were presented in frequency tables, percentages and means. The factors associated with risky sexual behaviours were identified by inferential statistics.

\section{RESULTS}

\section{Sociodemographic characteristics of respondents}

The demographic characteristics of participants are represented in Table 1. Data showed that $60 \%$ of the respondents were from the University of Port Harcourt, while $40 \%$ were from PAMO University of Medical Sciences.

The majority of the participants $(67.5 \%)$ were from the Department of Medicine and Surgery, while $32.5 \%$ were from the Department of Nursing Science. Only $1^{\text {st }}$ and $2^{\text {nd }}$ year students from the two departments participated in the study with the majority of the students (78.9\%) between $16-20$ years, while only $0.7 \%$ of the students were $\geq 31$ years. Most of the respondents $(98.9 \%)$ were single (unmarried), and the majority of them are females $(61.1 \%)$, while the males accounted for only $38.9 \%$.

\section{Age at First Intercourse}

Table 2 showed that out of the 94 (33.6\%) respondents that have had sexual contact, $14(14.9 \%)$ had first intercourse at age less or equal to 15 years, $63(67.0 \%)$ had first intercourse at age 1620 years and $17(18.1 \%)$ had first intercourse at age greater or equal to 21 years of age.

\section{Relationship between socio-demographic and variables (awareness, attitude and practices) of risky sexual behaviours.}

Table 3 showed that there is no significant relationship between respondents' sociodemographic variables (level of education, religion, sex, age and marital status) and awareness of risky sexual behaviour. There is also no significant relationship between respondents' sociodemographic variables and attitudes toward risky sexual behaviour. 
However, there is a significant association between respondents' sociodemographic and practices of risky sexual behaviour. Investigating each sociodemographic variable, the result revealed that only gender and age are significantly influenced by practices with an $R^{2}$ of 0.22 .

\section{DISCUSSION}

A study [12] recorded that risky sexual behaviours (RSB) are becoming an important problem all over the world. The study was carried out among medical and nursing undergraduate students from PAMO University of Medical Sciences and the University of Port Harcourt who are in the first and second year of their academic program. As shown in Table1, the majority of them are single or unmarried. Study findings recorded that less than half $(33.6 \%)$ of the respondents have had sexual contact. Data on table 2 revealed that about half of this number had first intercourse at an age less or equal to 15 years while the majority had first intercourse between 16 and 20 years of age. A slightly similar study [13] found that $64.4 \%$ of their respondents have had sexual intercourse at a mean age of 13.7 years. This indicates the resolution that initiation of early sexual intercourse predisposes young people to risky sexual behaviours and its attendant health consequences although there may be factors contributing to it.

A study [14] posited that its participants had good knowledge of what risky sexual behaviours mean as well as their consequences. Most female participants of the study condemned the act while expressing a carefree attitude towards risky sexual behaviours. They affirm that the "pleasure in a sexual relationship whether risky or not overrides the consequences". The majority of the participants affirmed to have been involved in risky sexual behaviours at one time or the other.

The study examined the relationship between sociodemographic variables (such as level of education, religion, sex, age and marital status) and risky sexual behaviours. This study found that certain sociodemographic data were significantly correlated to risky sexual behaviour as presented by data in table 3 . In the same manner, previous studies have indicated the same position. Rice et al [15] found race (e.g. black/African American) to be significantly associated with high-risk sexual behaviour. Findings from our study revealed that there is a significant relationship between marital status and awareness of risky sexual behaviour which is contrary to a study conducted among a representative group of sexually active women aged 18-24 years which documented that there was no correlation between risky sexual behaviour and sociodemographic factors.[16] On the other hand, the study [16] disagrees with that of Darteh, Dickson and Amu [17] which concluded that Risky Sexual Behaviour among young people was significantly associated with age, level of education, wealth status and religion. However, the reverse is the case among our respondents where the level of education, religion, gender and age did not significantly influence awareness of risky sexual behaviour.

Our study was conducted among unemployed undergraduate students; hence it neither analyzed nor recorded the influence of course of study (eg. Medicine and Surgery, Nursing Science) on risky sexual behaviour. Although, it was observed in the findings by Darteh, Dickson and Amu [17] in Kenya that employment status was related to risky sexual behaviours. It noted that males and females who were employed were less likely to engage in risky sexual behaviours than their unemployed counterparts. Our findings reiterate the need for relevant stakeholders 
including the Ministry of Health, Rivers State Health Service and Non-Governmental Organizations to intensify interventions focusing on improved health literacy among youths who are sexually active and this should be done with utmost priority.

Attitude to risky sexual behaviour varies with respect to the first time of sexual intercourse, the number of sexual partners, type of risky sexual behaviour practised and so on. Investigating the association of respondents' attitudes to risky sexual behaviours shows that there was no significant influence by their sociodemographic factors (level of education, religion, gender, age, marital status). This is in contrast to findings [18] which reported that older age was positively associated with not wanting to use condoms and not using condoms. In addition, people who use substances, such as shisha and heroin, are more likely to report not using condoms. Gender and employment significantly influenced attitudes and practices of risky sexual behaviours while the number of sex partners was not significantly associated with the want to use condoms.

Furthermore, the practise of risky sexual behaviours among the respondents of our study is significantly influenced by the age and gender of the respondents. Notwithstanding, a study [19] holds a similar position. It stated that only the effect on early sexual debut was gender invariant. These groups of respondents are often engaged with academic activities and will benefit from school-based social programs aimed at reducing the practice of risky sexual behaviour. The importance of such programs cannot be overemphasized.

According to a study [11] conducted in the year, 2020 concluded that only age, marital status, ever fathered/mothered any children, level of education, employment status, wealth index, and ethnicity respectively had significant relationships with age at first sexual intercourse. It also documented that only the sex of respondents, marital status, ever fathered/mothered any children, ever heard of AIDS, level of education, employment status, wealth index, and ethnicity respectively had a significant influence on condom use at first and last sexual intercourse. However, our data recorded no significant relationship between respondents' practice of risky sexual behaviours and level of education, religion and marital status. This could be due to stigma for sexual promiscuity as in multiple sexual partners and the lack of power to negotiate protection may curtail the significance level of influence of these factors on respondents' practice of risky sexual behaviour. To further counteract our study findings, a study titled "Risky sexual behaviour and predisposing factors among students of Jimma University, Ethiopia" [20] noted that religiosity has been found to be a protective measure against Risky Sexual Behaviour.

\section{CONCLUSIONS}

The significance of the influence of certain sociodemographic variables and risky sexual behaviours has become a course concern. The study recommends that effective sexual interventions focusing on risky sexual behaviour must address risk factors.

Conflicts interest: "Authors declared they have no conflicts of interest". 


\section{Authors' contributions:}

OEO prepared instruments for data collection, analyzed and interpreted data, reviewed and approved the manuscript/article for submission. UOA drafted the introduction and structured the topic, obtained data and prepared/drafted the manuscript. OIN reviewed related literature, designed the methodology and reviewed the manuscript. OEN applied for ethical approval, reviewed the introduction and took part in data collection. All authors have critically reviewed and approved the final draft and are responsible for the content and similarity index of the manuscript.

\section{Acknowledgements}

We wish to acknowledge Osuala O, Udi O, Ogbu B, Ojong I and Oduali E for their contribution to the conception of the study, study design, acquisition of data, analysis and interpretation of data, drafting the manuscript and revising same in order to achieve intellectual content.

\section{Tables}

Table 1: sociodemographic characteristics of respondents

Table 2: Age at First Intercourse

Table 3: Relationship between socio-demographic and variables (awareness, attitude and practices) of risky sexual behaviours.

\section{REFERENCES:}

[1]. Awoke D, Mekonnen A, Daniel M, Fantahun B. Risky sexual behaviour and associated factors among students of Debre Tabor University, Northwest Ethiopia: a crosssectional study. Ethiopia Journal of Health Development. 2016;30(1):11-18

[2]. Dennis M, Peter W, Marion M, Peter N. Sexual Risky Behaviors among the Youth in Kenya. Medicine Science/International Medical Journal. 2012;1(3):177-187.

[3]. Alamrew Z, Bedimo M, Azage M. Risky Sexual Practices and Associated Factors for HIV/AIDS Infection among Private College Students in Bahir Dar City, Northwest Ethiopia. International Scholarly Research Notices. 2013;2013(2):1-9.

[4]. Paul HG. Human Sexual Activity. Encyclopedia Britannica. 2019. Retrieved March 1, 2019, from https://www.britannica.com/topic/human-sexual-activity

[5]. Glen-Spyron C. Risky Sexual Behavior in Adolescence. Available at: www.bellavidacentre. co.za. Accessed on $22^{\text {nd }}$ October 2019.

[6]. Center for Disease Control: Adolescent and school health. Alcohol and other drug use. 2016. Available at: https://www.cdc.gov/healthyyouth/data/topics/index.htm. Accessed on 7 July 2019.

[7]. Kebede, A., Molla, B. \& Gerensea, H. Assessment of risky sexual behaviour and practice among Aksum University students, Shire Campus, Shire Town, Tigray, Ethiopia. BioMedical Central Research Notes. 2018;11(1):88

[8]. Ajayi AI, Nwokocha EE, Akpan W, Adeniyi OV, Goon DT. It's Sweet without Condom: Understanding Risky Sexual Behaviour Among Nigerian Female University Students. Online Journal of Health \& Allied Sciences. 2017;16 (4):9. 
[9]. Odimegwu C, Dolapo OS. Ethnicity, gender and risky sexual behaviour among Nigerian youths: An alternative explanation. BioMedical Central Journal. 2017;14(1):16.

[10]. Ayinmoro AD, Uzobo E, Teibowei BJ, Fred JB. Sexting and other risky sexual behaviour among female students in a Nigerian academic institution. Journal of Taibah University of Medical Sciences. 2020;15(2): 116-121.

[11]. Okunlola DA, Alawode OA, Bolarinwa OA, Agbeja IO, Awoyele AF. SocioDemographic, Economic and Psychological Correlates of Risky Sexual Behaviour among Sexually Active Young People in Nigeria. Global Journal of Health Science. 2020;12(8):9-26.

[12]. Perera UA, Abeysena C. Prevalence and associated factors of risky sexual behaviours among undergraduate students in State Universities of Western Province in Sri Lanka: A descriptive study. Reproductive Health Journal. 2018;15(105).

[13]. Akumiah PO, Suglo JN, Sebire SY. Early life exposures and risky sexual behaviours among adolescents: A cross-sectional study in Ghana. Nigerian Medical Journal. 2020; 61(4):189-195

[14]. Osuala E, Ogbu B, Udi O. Risky Sexual Behaviour among Students of Tertiary Institutions in South-South, Nigeria: A Qualitative Study. Health. 2020; 12: 1095-1104

[15]. Rice E, Rhoades H, Winetrobe H, Sanchez M, Montoya J, Plant A, Kordic T. Sexually explicit cell phone messaging associated with sexual risk among adolescents. Paediatrics. 2012; 130(4):667-673

[16]. Krepelka P, Thomas F, Urbankova I, Hanacek J, Krofta L, Dvorak V. Risky Sexual Behaviour and Contraceptive Use among young women in the Czech Republic. Central European Journal of Public Health. 2020;20(1):3-12.

[17]. Darteh EKM, Dickson KS, Amu H. Understanding the Socio-demographic Factors Surrounding Young Peoples' Risky Sexual Behaviour in Ghana and Kenya. Journal of Community Health. 2020;45(1):141-147

[18]. Ngoc DH, Ngoc ND, Quynh TNH, Tuan NA, Duy NH, Phuong BT, Bich TVT, Thanh LK, Tuan ND, Tat NC, Gia VL, Thu VG, Xuan TB, Latkin CA, Ho RCM, Ho CSH. Patterns of Risky Sexual Behaviors and Associated Factors among Youths and Adolescents in Vietnam. International Journal of Environmental Research and Public Health. 2020;17(6):1903.

[19]. Lin W-H, Liu C-H, Yi C-C. Exposure to sexually explicit media in early adolescence is related to risky sexual behaviour in emerging adulthood. PLoS ONE. 2020;15(4):230242.

[20]. Tura G, Alemseged F, Dejene S. Risky sexual behaviour and predisposing factors among students of Jimma University, Ethiopia. Ethiopia Journal of Health Science. 2012;22(3):170-80. 


\section{APPENDIX}

Table 1: Sociodemographic characteristics of respondents

\begin{tabular}{|c|c|c|}
\hline & Frequency $(n=280)$ & Percentages (\%) \\
\hline \multicolumn{3}{|l|}{ Institution } \\
\hline Uniport & 168 & 60.0 \\
\hline PAMO & 112 & 40.0 \\
\hline \multicolumn{3}{|l|}{ Department } \\
\hline Nursing & 91 & 32.5 \\
\hline Medicine & 189 & 67.5 \\
\hline \multicolumn{3}{|l|}{ Level of Edu. } \\
\hline $1^{\text {st }}$ Year & 155 & 55.4 \\
\hline $2^{\text {nd }}$ Year & 125 & 44.6 \\
\hline \multicolumn{3}{|l|}{ Age (years) } \\
\hline $16-20$ & 221 & 78.9 \\
\hline $21-25$ & 51 & 18.2 \\
\hline $26-30$ & 6 & 2.1 \\
\hline$\geq 31$ & 2 & 0.7 \\
\hline Mean \pm Std & $19.42 \pm 2.46$ & \\
\hline $95 \% \mathrm{CI}$ & $19.13-19.71$ & \\
\hline \multicolumn{3}{|l|}{ Religion } \\
\hline Anglican & 41 & 14.6 \\
\hline Roman Catholic & 52 & 18.6 \\
\hline Pentecostal & 155 & 55.4 \\
\hline Moslem & 8 & 2.9 \\
\hline African Tradition & 2 & 0.7 \\
\hline Others & 22 & 7.9 \\
\hline \multicolumn{3}{|l|}{ Sex } \\
\hline Male & 109 & 38.9 \\
\hline Female & 171 & 61.1 \\
\hline \multicolumn{3}{|c|}{ Marital Status (MS) } \\
\hline Single & 277 & 98.9 \\
\hline Married & 3 & 1.1 \\
\hline
\end{tabular}


African Journal of Health, Nursing and Midwifery

ISSN: 2689-9418

Volume 4, Issue 5, 2021 (pp. 102-111)

www.abjournals.org

Table 2: Age at First Intercourse

\begin{tabular}{ll}
\hline Age (yrs.) $(\mathbf{n = 9 4 )}$ & Frequency $(\%)$ \\
\hline$\leq 15$ & $14(14.9)$ \\
$16-20$ & $63(67.0)$ \\
$\geq 21$ & $17(18.1)$ \\
\hline
\end{tabular}

Table 3: Relationship between socio-demographic and variables (awareness, attitude and practices) of risky sexual behaviours.

\begin{tabular}{lllllll}
$\begin{array}{l}\text { Dependent } \\
\text { Variable }\end{array}$ & $\begin{array}{l}\text { Independent } \\
\text { Variables } \\
\text { (Socio-Demographic) }\end{array}$ & $\begin{array}{l}\text { t-statistic } \\
\text { (p-value) }\end{array}$ & R & $\mathbf{R}^{2}$ & $\begin{array}{c}\text { F-Statistic } \\
\text { (p-value) }\end{array}$ & Decision \\
\hline Awarions & & & &
\end{tabular}

$\begin{array}{lllllll}\text { HO1 Awareness } & \text { Level of Edu. } & 1.125(0.262) & 0.192 & 0.037 & 2.098 & \text { No } \\ & \text { Religion } & -0.367(0.714) & & & (0.066) & \text { Significant } \\ & \text { Sex } & 1.047(0.296) & & & & \text { Relationship } \\ & \text { Age } & 1.606(0.110) & & & & \\ \text { MS2 Attitude } & \text { LS } & -2.679(0.008) & & & & \\ & \text { Level of Edu. } & -0.155(0.877) & 0.173 & 0.030 & 1.700 & \text { No } \\ & \text { Religion } & 0.665(0.506) & & & (0.135) & \text { Significant } \\ & \text { Sex } & -1.681(0.094) & & & & \text { Relationship } \\ & \text { Age } & 1.800(0.073) & & & & \\ \text { HO3 Practices } & \text { MS } & -0.851(0.396) & & & & \\ & \text { Level of Edu. } & -1.083(0.282) & 0.470 & 0.221 & 4.984 & \text { Significant } \\ & \text { Religion } & 0.694(0.489) & & & (0.000) & \text { Relationship } \\ & \text { Sex } & -3.486(0.001) & & & & \\ & \text { Age } & 2.837(0.006) & & & & \end{array}$

